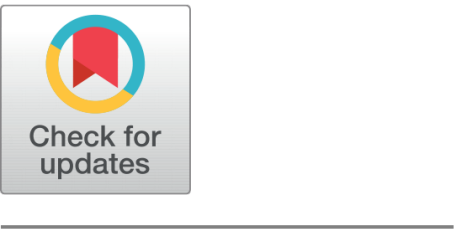

G OPEN ACCESS

Received: 16.03.2021

Accepted: 19.01.2022

Published: 04.02.2022

Citation: Vishal P, Kumar MK (2022) Application of Ultrasound Sensor in Construction Safety: Study of Struck-By Hazard. Indian Journal of Science and Technology 15(4):

146-157. https://doi.org/

10.17485/IJST/v15i4.453

* Corresponding author.

kranti.myneni@spav.ac.in

Funding: None

Competing Interests: None

Copyright: (c) 2022 Vishal \& Kumar. This is an open access article distributed under the terms of the Creative Commons Attribution License, which permits unrestricted use, distribution, and reproduction in any medium, provided the original author and source are credited.

Published By Indian Society for Education and Environment (iSee)

ISSN

Print: 0974-6846

Electronic: 0974-5645

\section{Application of Ultrasound Sensor in Construction Safety: Study of Struck-By Hazard}

\author{
P Vishal ${ }^{1}$, M Kranti Kumar ${ }^{2 *}$ \\ 1 Post Graduate Student, Department of Architecture, School of Planning and Architecture, \\ Andhra Pradesh, 520008, Vijayawada, India \\ 2 Assistant Professor, Department of Architecture, School of Planning and Architecture, \\ Andhra Pradesh, 520008, Vijayawada, India
}

\section{Abstract}

Objectives: To accesses the impact of the sensors in preventing from struck-by hazards in the construction sites; To compare the suitability of available sensor technologies in prevention system of struck-by hazard. Method: The current demand of construction industry is to complete project in the minimum time, to achieve the goal of safety as construction sites are getting complex in terms of management challenge. Available proximity sensors were examined to choose an appropriate sensor for using in early warning system to prevent from struck-by hazards. An early warning system was proposed using ultrasound sensor, that will warn the vehicle operator by visual and acoustical methods to stop the vehicle before collision between vehicle and personal / equipment I material and will prevent from struck-by hazards. Findings: It has been proven that blind spots (visibility problem) are the main reason for struckby accidents. Ultrasound sensors uses sound technology, so that, they are suitable to detect objects in non-visible conditions (Rain, Fog, Night etc.). Ultrasound technology is independent and does not necessitate external hardware installation or processing facilities once it is integrated on the machinery. Proposed early warning system will help construction managers to manage sites more effectively. Novelty: Many researchers have done various studies on struck-by hazard prevention in construction. However, there is no enough focus on, particularly using ultrasound sensors to prevent from struckby hazards. Hence to assess the capability and use of ultrasound sensors in this area of construction is been done

Keywords: Construction Safety; Safety Management; Ultrasound Sensor; Struckby Hazard; Prevention System; Early Warning System

\section{Introduction}

Owing to the harsh work climate and high risks involved, construction industry has become one of the most dangerous industries. Although the construction industry in developing countries is often considered risky compared to developed countries such as the United States and the United Kingdom. The accident death and injury rate are 
respectively three and two times higher than the average of other industries, according to global statistical statistics.

The Bureau of Labor Statistics (BLS), USA reported that, in annual report 2018, from a total of 5250 fatalities, 1008 were occurred in construction industry and from these 1008 fatalities, 250 (25\%) were attributed to struck-by hazard [Figure 1]. The Health and Safety Executive (HSE), UK reported that, in annual report 2019, from a total of 147 fatalities, 30 were occurred in construction industry and from these 30 fatalities, 6 (20\%) were attributed to struck-by hazard [Figure 2].

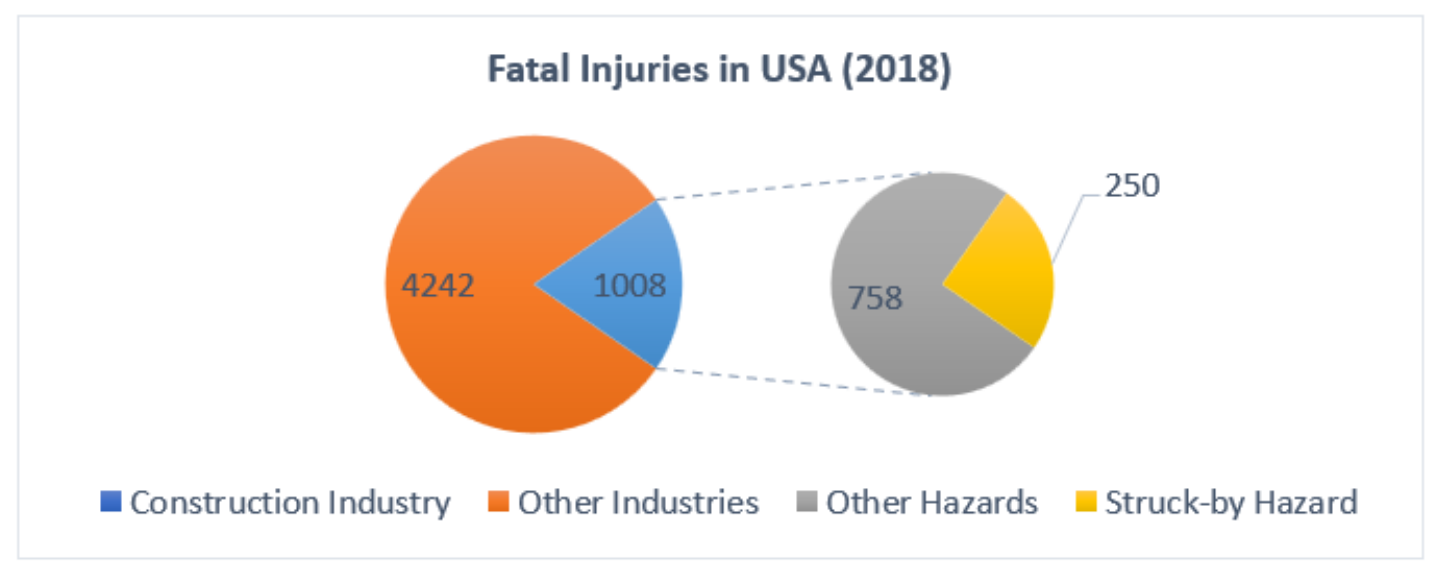

Fig 1. Fatal Injuries in USA (2018) due to Struck-by Hazard

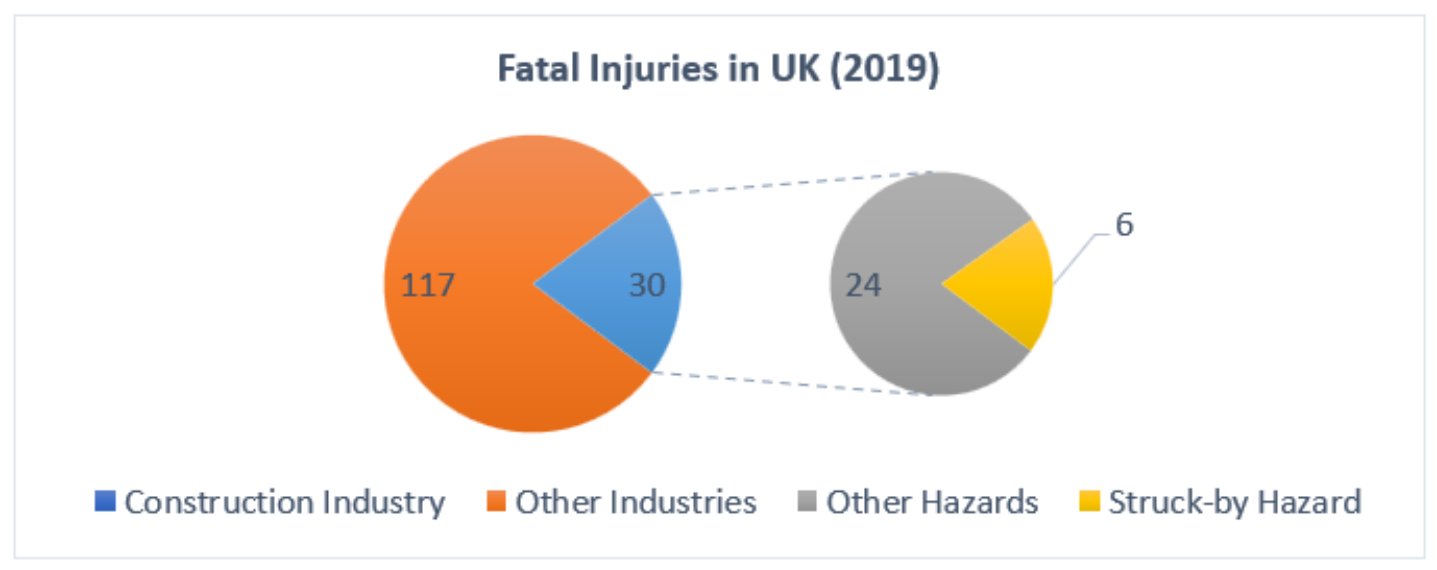

Fig 2. Fatal Injuries in UK (2019) due to Struck-by Hazard

The Safe Work Australia (SWA), Australia reported that, in annual report 2019, from a total of 183 fatalities, 26 were occurred in construction industry. From year 2015 to 2019 a total of 916 fatalities, 150 were occurred in construction industry and from these 150 fatalities, 26 (17\%) were attributed to struck-by hazard [Figure 3].

\subsection{Need of the Research}

Construction sites are getting complicated due to the demand for faster completion of the project. Traditional methods of safety management for complex work are making safety management at the site more difficult. The conventional safety management approach cannot full fill the requirements of safety due to continuous inputs and real-time changes at the construction site. The adoption of various sensors-based safety management practice can provide exact location and visuals of hazards present at the site. 


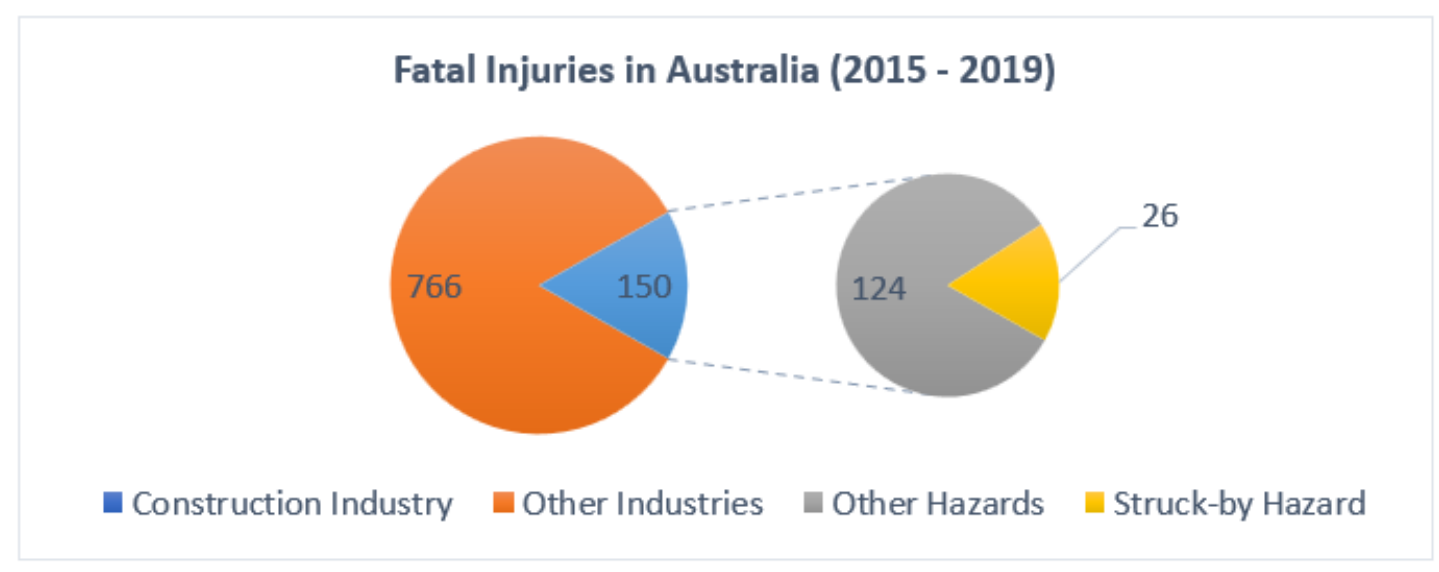

Fig 3. Fatal Injuries in Australia (2015 - 2019) due to Struck-by Hazard

\subsection{Research Gap and Objective}

This research, therefore, seeks to examine how to prevent from struck-by hazards to reduce accidents in the construction sites. There are various studies on struck-by hazard prevention in construction sites conducted by various researchers. However, there is a dearth of studies, particularly using ultrasound sensors to prevention from struck-by hazards, that has made an attempt to assess the capability of ultrasound sensors to prevention from struck-by hazards in construction sites. Hence, this research will review the applicability of ultrasound sensors in construction safety management to prevention from struck-by hazards and compare ultrasound sensor applicability at construction site from different available proximity sensors.

\subsection{Struck-by Hazards}

Struck-by Hazards are those that causes injuries that are produced by forcible contact or impact of an object or piece of object on a person. Here the word struck refers to the event in which the ramming of the object is the alone cause of the fatality. According to OSHA, Struck- by hazards are classified as: 1) Struck-by flying object, these are the hazards that are caused when something is hurled, thrown or is catapulted over the space. It can be caused by a piece of material, tool or machine, which strikes the personal and result in injury. It is also considered as a flying objected hazard if an object is forced to be thrown out by subjecting it to high pressure using a tool or equipment such as a nail gun. 2) Struck-by falling object, if the casualty is caused by a source that is falling from an elevation it is termed as falling object hazard. It also includes events in which the person is getting crushed, pinned or caught under the falling objects, other than collapse of structure or building material. 3) Struck-by swinging object, these are those that result in injuries caused by the objects that has the potential to swing and strike workers. This also includes events where injuries are causes by the retracting motion of objects due to which the workers can be struck by. It occurs mainly due to the swinging and twisting motion of materials that are caused to its manual lifting. The position of the worker and the force behind the load decides the extent of injury. 4) Struck-by rolling object, if the hazards are caused by the rolling or sliding motion of an object at the same level where workers are located, then it is categorized as Struck-by rolling object hazards. The fatalities caused by the running over of a moving vehicle without being caught under it can also be grouped under this category.

Traditionally, visual observations are also used in construction to track struck-by risks ${ }^{(1)}$. These techniques, are expensive and time taking and struggle from the disadvantages of unreliable calculation of proximity. Recently, considerable research efforts have been made to automate the struck-by hazard detection in construction. Some studies applied wireless sensorssuch as Radio Frequency Identification (RFID) ${ }^{(2)}$, Magnetic Field (MF), Global Positioning System (GPS), and Bluetooth Low Energy (BLE)to instantly detect hazardous proximity between entities of interest. On the other hand, other studies applied deep neural networks (DNNs)-based object detection framework - such as Faster R-CNN ${ }^{(3)}$, R-FCN ${ }^{(4)}$, and YOLO-V3 ${ }^{(5)}$ for continuous object localization and proximity monitoring. Author of ${ }^{(6)}$ has built a trajectory prediction model for building mobile resources to help effective struck-by-hazard identification in construction. In particular, a deep neural network called Social GAN performed hyper-parameter tuning and developed a prediction model able to predict the trajectory of the target for more than five seconds. 
Computer Vision-based (CVB) three-dimensional spatial distance as well as crowdedness prediction approach was developed based on two-dimensional object recognition, three-dimensional bounding box rebuilding, and depth estimation by the author of ${ }^{(7)}$ to detect struck-by hazards in monocular $2 \mathrm{D}$ vision. The author of ${ }^{(8)}$ developed GPS-based resource location tracking systems, identified weighted parameters for threat level calculation, and described preliminary test findings on safety heat maps which mapped near-missing site layout information in building information models. An integrated system of information management with real-time location monitoring has been proposed, implementing RFID for access control of personnel, equipment and materials. All system components are incorporated into a network of RFID sensors.

Innovations such as radio-frequency identification (RFID), ultrasonic, radar, infrared and others have been used and built to avoid collisions as distance warning systems for construction. For example, in construction work zones, ultrasonic and pulsed radar have been introduced explicitly for back-over protection practices. The efficiency of the sensing systems developed (ultrasonic and pulsed radar, respectively) was assessed under variable circumstances, including the installation of sensors, the static test, the dynamic test and the dirty sensor test. In another research, wireless sensing technology focused on Bluetooth (iBeacon) was used to detect personnel who broke into dangerous areas around equipment, along with auxiliary components to help sound warning, vibration and visualization. A loader and a dumping trailer are used to determine the unit detection distance, which is the distance in between transmitters and the collector. Magnetic field detection and actuation technology has also been used to alert staff to become too close in real time to heavy machinery.

The various researchers implemented their experiments and came up with their own monitoring systems for the struck-by hazard at the construction site. Based on their analysis the following research is an experimentation on the real time monitoring framework by using ultrasonic sensors.

However, there is a dearth of studies, particularly using ultrasound sensors to prevention from struck-by hazards, that has made an attempt to assess the capability of ultrasound sensors to prevention from struck-by hazards in construction sites. Hence, this research will review the applicability of ultrasound sensors in construction safety management to prevention from struck-by hazards and compare ultrasound sensor applicability at construction site from different available proximity sensors.

\section{Application of Ultrasound Sensor in Construction Safety}

\subsection{Site Characteristics}

Two different factors consist of a building work environment. The first factor would be the area in which project is located, as well as the other would be the resources associated with the construction activities (workers, equipment, and materials). A number of connections among building machinery, staff and goods distinguish worksites. Its dynamic development causes a variety of visibility issues. Workforce and machinery operators are usually concerned with knowing each other on a worksite as well as in real time. Site layout would be the geometric framework wherein the work is carried out. Land type, soil condition, existing structures, and provisional site logistics based on already planned and constantly revised site detailed designs are of this kind.

One of the major contributors of interaction accidents among personnel on the ground and heavy machinery is non-visible areas and known as blind spots. Blind spots block visibility of construction machinery operator by Producing invisible zones beyond the machine cabinet for the machine controller. Among other causes, interaction accidents occur when personnel, machinery, or goods penetrate Such blind spots have not been identified by the controller of the machinery.

The sight issues for operators provide an influence on the entire safety efficiency of the project. Equipment blind spots ${ }^{(9)}$ are one of the reasons to the interaction accidents among construction vehicles and personnel. Blind spots become a poorly visible commodity in which the machinery controller's visible range is obstructed by machinery components as well as objects present in the site. Sometimes distance of labor on ground to construction vehicles causes several visibility issues for operators. Statistics discovered in research ${ }^{(9)}$ provide existence of this issue. This incident analysis revealed the blind spot problems related to sight, formulated controllers to (1) drive over personnel and goods, (2) smash other machinery, and (3) roll back when driving their same construction vehicles ${ }^{(9)}$.

\subsection{Visibility and Blind Spots for Equipment Operator}

Blind spots are the areas which are not clear to the machinery controller around a heavy machinery ${ }^{(10)}$. It was also estimated that 75 percent of all struck-by incidents are influenced by visibility problems ${ }^{(1)}$. A thorough description of reasons [Figure 4] as well as movement directions [Figure 5] for visibility-related incidents are provided. Blind spots of machines could be calculated through physical and software techniques. The physical solution includes using a seat index point system to position a nonnatural light source at the sight view of the operator. Then, it tests the clarity of the test screen. For the computer simulation 
process, computer-aided design (CAD) models were used to construct a blind spot figure using non-natural light source. To create and validate blind spot areas surrounding machinery dynamically, a three-dimensional point cloud from a laser scanner have recently been introduced.

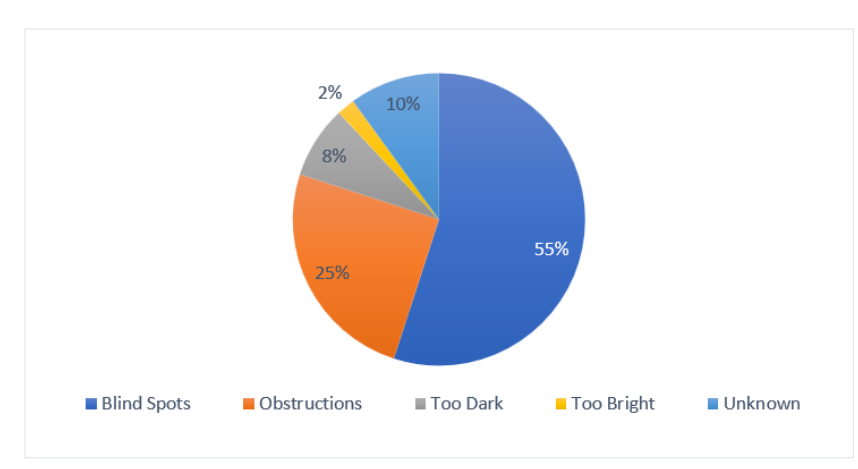

Fig 4. AccidentsAssociated to Visibility (1990 - 2007) Classified by Cause

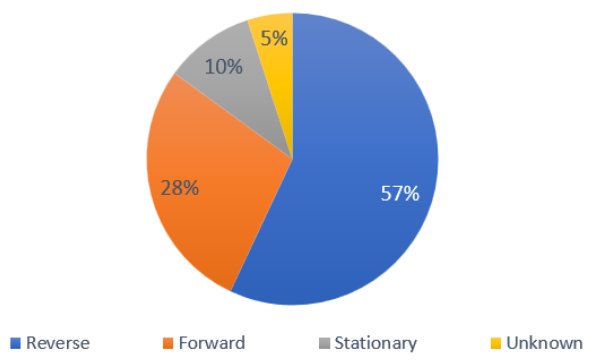

Fig 5. Visibility-relatedFatalities (1990-2007) Classified by Equipment Travel Direction

\subsection{Speed Limit at Construction Site}

As per Health and Safety Executive (HSE), Government of UK, to restrict the probability and seriousness of incidents, speed limits should be enforced on construction sites. Acceptable site speed limits should be $10-20 \mathrm{miles} / \mathrm{h}$ (16-32 Km/h), depending on the vehicles used, site layout and hazards, accounting for the type of vehicles using, the roadway width and its layout, curves, visibility at junctions etc. This should then be clearly conveyed to operators of all vehicles needing entry to the site, sign-posted and implemented at reasonable intervals and places to remind operators of the speed limit. The limits should be implemented by site security and supervisors in order to be successful. Speed limits and appropriate corrective action taken as applicable should be included in the site rules.

From the previous sections, we know highest (57\%) visibility-related fatalities are occurred while reversing an equipment. Author ${ }^{(8)}$ collected width and maximum reversing speed for various common construction vehicles from US based construction equipment company, John Deere [Table 1]. 
Table 1. Specificationsof Construction Equipment

\begin{tabular}{lllll}
\hline \multirow{2}{*}{ Equipment } & \multirow{2}{*}{ Model } & \multirow{2}{*}{$\begin{array}{l}\text { Width } \\
(\text { Ft.) }\end{array}$} & \multicolumn{2}{l}{ Max. Reverse Speed } \\
\cline { 5 - 5 } & & & Miles / hour & $\mathbf{K m} /$ hour \\
\hline Backhoe & $310 \mathrm{SG}$ & 7.05 & 20.5 & 32 \\
Dump Truck & 400D & 11.08 & 4 & 6.43 \\
Crawler Loader & 755C & 8.17 & 6.8 & 10.94 \\
Excavator & 650D LC & 12.25 & 3 & 4.82 \\
4WD Loader & 844J & 11.46 & 17 & 27.35 \\
\hline
\end{tabular}

\subsection{Maximum Stopping Distance}

The stopping distance is the distance a vehicle travels from the stage at which its brake pads are completely activated and then when a full stop is attained. Ministry of Road Transport and Highways (MoRTH), Government of India, conducted a test on construction earth moving machine and equipment to determine the formula [Equation 1] of calculating stopping distance of construction earth moving machine and equipment (in meter) after applying service brake.

Equation $1 \widehat{v} 2 / 130+0.15(v)$

Here, $\mathrm{v}=$ Vehicle Speed, in $\mathrm{Km} / \mathrm{h}$

\subsection{Struck-by Hazard Early Warning System Design Approach}

The speed limit at construction site is determined as $16-32 \mathrm{Km} / \mathrm{h}$ by HSE and maximum reverse speed of various common construction vehicles is $32 \mathrm{Km} / \mathrm{h}$ or below [Table 1]. So, we can consider $32 \mathrm{Km} / \mathrm{h}$ as maximum speed of vehicle to design the hazard detection system. After using $32 \mathrm{Km} / \mathrm{h}$ as vehicle speed in the formula given by Ministry of Road Transport and Highways (MoRTH), Government of India, we will get 12.68 meters (41.6 ft.) as stopping distance of construction earth moving machine and equipment after applying service brake.

So, the hazard detection system should be designed in a way that, object at the distance of $42 \mathrm{ft}$. (rounded off) or $12.80 \mathrm{~meter}$ should be detect by the system and will ensure that, the designed hazard detection system will work in the extreme condition that is, when vehicle moving in the speed of $32 \mathrm{Km} / \mathrm{h}$.

\subsection{Ultrasound Sensors in Struck-by Hazard Early Warning System}

The proposed method is an approach to develop a "Struck-by" hazard prevention method by using ultrasound sensors. The idea is to detect personals on the way of moving vehicles in the construction sites and warn the driver about the hazardous situations near them. Where ultrasound sensor is used to identify the personals present on the way of moving vehicle from the distance of $42 \mathrm{ft}$. (rounded off) or 12.80 meter when vehicle moving in the highest speed of $32 \mathrm{Km} / \mathrm{h}$ within the construction site.

\section{Inferences}

The goal of this study includes to improve situation - specific perception and prevention in construction equipment activity by using pro-active wireless forewarning and alarm devices independently working when construction resources (manpower, machinery, and materials) become too nearby. Sensor-based technologies could address workforce and controller of equipment to track relative closeness to each other. Visual, acoustic, and vibration warnings activate when distance gets too close to alert operators about machinery.

\subsection{Selection of Technology}

The requirements for distance alert system and alarm process selection have been set out in [Table 2] including certain primary systems suitable to be used in the field of safety in construction ${ }^{(2)}$. National Institute for Occupational Safety and Health, USA proposed "Recommendations for Evaluating and Implementing Proximity Warning Systems on Surface Mining Equipment", the author also documented fatal incidents linked with persons located in the construction equipment blind spot zone. They checked that several distance technologies are feasible, but each technology has disadvantages. They also concluded "a proximity warning system evaluation must be conducted on the actual equipment where it will be installed before any conclusions can be made about reliable detection areas, false alarm rates, or alarm effectiveness." Because each part of machinery is unique, 
Table 2. Properties of Proximity Warning and Alert Technologies

\begin{tabular}{|c|c|c|c|c|c|c|c|c|c|c|c|c|}
\hline Infrared & $\begin{array}{l}\text { Proxim- } \\
\text { ity }\end{array}$ & $\begin{array}{l}0- \\
30\end{array}$ & Low & Medium & Small & No & Good & High & Small & Small & $\begin{array}{l}\text { Line-of- } \\
\text { sight }\end{array}$ & $\begin{array}{l}\text { Inexpen- } \\
\text { sive }\end{array}$ \\
\hline $\begin{array}{l}\text { Optical } \\
\text { eye- } \\
\text { safe laser } \\
(1 \mathrm{D} / 2 \mathrm{D} / 3 \mathrm{D})\end{array}$ & $\begin{array}{l}\text { Loca- } \\
\text { tion }\end{array}$ & $\begin{array}{l}0- \\
50\end{array}$ & High & Small & High & No & $\begin{array}{l}\text { Very } \\
\text { Good }\end{array}$ & High & Medium & Mediun & $\begin{array}{l}\text { Line-of- } \\
\text { sight }\end{array}$ & Location \\
\hline Stereo/video & $\begin{array}{l}\text { Proxim- } \\
\text { ity \& } \\
\text { Dis- } \\
\text { tance }\end{array}$ & $\begin{array}{l}0- \\
500\end{array}$ & Medium & Small & High & No & Poor & High & Small & Small & $\begin{array}{l}\text { Segmen- } \\
\text { tation }\end{array}$ & $\begin{array}{l}\text { Location } \\
\text { \& Range }\end{array}$ \\
\hline $\begin{array}{l}\text { Very-high } \\
\text { frequency } \\
\text { (VHF) }\end{array}$ & $\begin{array}{l}\text { Proxim- } \\
\text { ity }\end{array}$ & $\begin{array}{l}0- \\
500\end{array}$ & Medium & High & Small & Yes & $\begin{array}{l}\text { Very } \\
\text { Good }\end{array}$ & High & Small & Small & $\begin{array}{l}\text { Omni } \\
\text { direc- } \\
\text { tional } \\
\text { signal }\end{array}$ & $\begin{array}{l}\text { Long } \\
\text { Range }\end{array}$ \\
\hline $\begin{array}{l}\text { RF ultra- } \\
\text { high } \\
\text { frequency } \\
\text { (UHF) }\end{array}$ & $\begin{array}{l}\text { Proxim- } \\
\text { ity }\end{array}$ & $\begin{array}{l}0- \\
40\end{array}$ & Medium & Small & Small & Yes & $\begin{array}{l}\text { Very } \\
\text { Good }\end{array}$ & High & Small & Small & $\begin{array}{l}\text { Proxim- } \\
\text { ity }\end{array}$ & $\begin{array}{l}\text { Works in } \\
\text { high } \\
\text { metal } \\
\text { area }\end{array}$ \\
\hline Ultrasound & $\begin{array}{l}\text { Dis- } \\
\text { tance }\end{array}$ & $\begin{array}{l}0- \\
20\end{array}$ & Medium & High & Small & No & $\begin{array}{l}\text { Very } \\
\text { Good }\end{array}$ & High & Small & Small & $\begin{array}{l}\text { Short } \\
\text { range }\end{array}$ & $\begin{array}{l}\text { Inexpen- } \\
\text { sive }\end{array}$ \\
\hline $\begin{array}{ll}\text { Tech- } & \text { Cri- } \\
\text { nol- } & \text { te- } \\
\text { ogy } & \text { ria }\end{array}$ & $\begin{array}{l}\text { Objec- } \\
\text { tive }\end{array}$ & $\begin{array}{l}\text { Range } \\
(\mathrm{M})\end{array}$ & $\begin{array}{l}\text { Accu- } \\
\text { racy } \\
\text { of } \\
\text { data }\end{array}$ & $\begin{array}{l}\text { Sig- } \\
\text { nal } \\
\text { bounce }\end{array}$ & $\begin{array}{l}\text { Data } \\
\text { process- } \\
\text { ing } \\
\text { effort }\end{array}$ & $\begin{array}{l}\text { Secure } \\
\text { sig- } \\
\text { nal }\end{array}$ & $\begin{array}{l}\text { Day } \\
\text { vs. } \\
\text { night }\end{array}$ & $\begin{array}{l}\text { Signal } \\
\text { update } \\
\text { rate }\end{array}$ & $\begin{array}{l}\text { Size } \\
\text { and } \\
\text { weight }\end{array}$ & $\begin{array}{l}\text { Pur- } \\
\text { chase } \\
\text { cost }\end{array}$ & $\begin{array}{l}\text { Main } \\
\text { barriers }\end{array}$ & $\begin{array}{l}\text { Main } \\
\text { benefits }\end{array}$ \\
\hline
\end{tabular}

they checked that "a system that works well on haul trucks may not be suitable for excavators", also "detection range would automatically adjust to equipment travel speed". As ultrasound sensors works on the sound wave system, it does not have any blind spot for the vehicle driver and most appropriate for the proximity warning system.

\subsection{Usage of Ultrasound Sensor}

The chosen ultrasound technology is independent and does not necessitate external hardware installation or processing facilities once it is integrated on the machinery. This shows strong value for implementations in the management of construction safety. The technology applies a sound waves spectrum to detect if sound waves those were sent previously comes within specified time. Once the signal intensity defined by the user is met, safe warning or alarm signals are transmitted in real-time. The ultrasound sensor occupied devices can alert and interrupt the operator's attention on their job by lighting up the emergency light (visual) or starting the danger hooter (acoustical) warning, causing the operator to re-assess the current condition; too many incidents happened because operators are become comfortable to the job atmosphere in the region on the basis of practical experience. This study will enable to find an alternative way to incorporate this system in workplace activities and the adoption and trust of the system by personnel. The whole study will offer a structure for further research to develop a "near-misses" and overall "real-time data" documentation system for a tragedy that is still largely not applied in the infrastructure sector. This study would include quantitative evaluation of distance solutions and additional evaluation of equipment blind spots and attempts to identify acceptable safety regions for construction machinery.

\section{Discussions}

Ultrasound sensors are fitted with an emitter that throws out a burst of sound waves at a frequency of about $60 \mathrm{kHz}$, which is beyond the human listening spectrum. The wave moves at the speed of sound away from the sensor and can be reflected back in the form of an echo by things in front of the sensor. It requires an echo to return to the sensor by calculating the time, and the distance to the subject can be reliably measured using the formula [Equation 2].

$D=t \times v / 2$

Here, $\mathrm{D}=$ Distance to the object

$\mathrm{t}=$ Time taken by the echo to come back 
$\mathrm{v}=$ Speed of sound $(\mathrm{m} / \mathrm{s})$

\section{IRU-3430 Specifications}
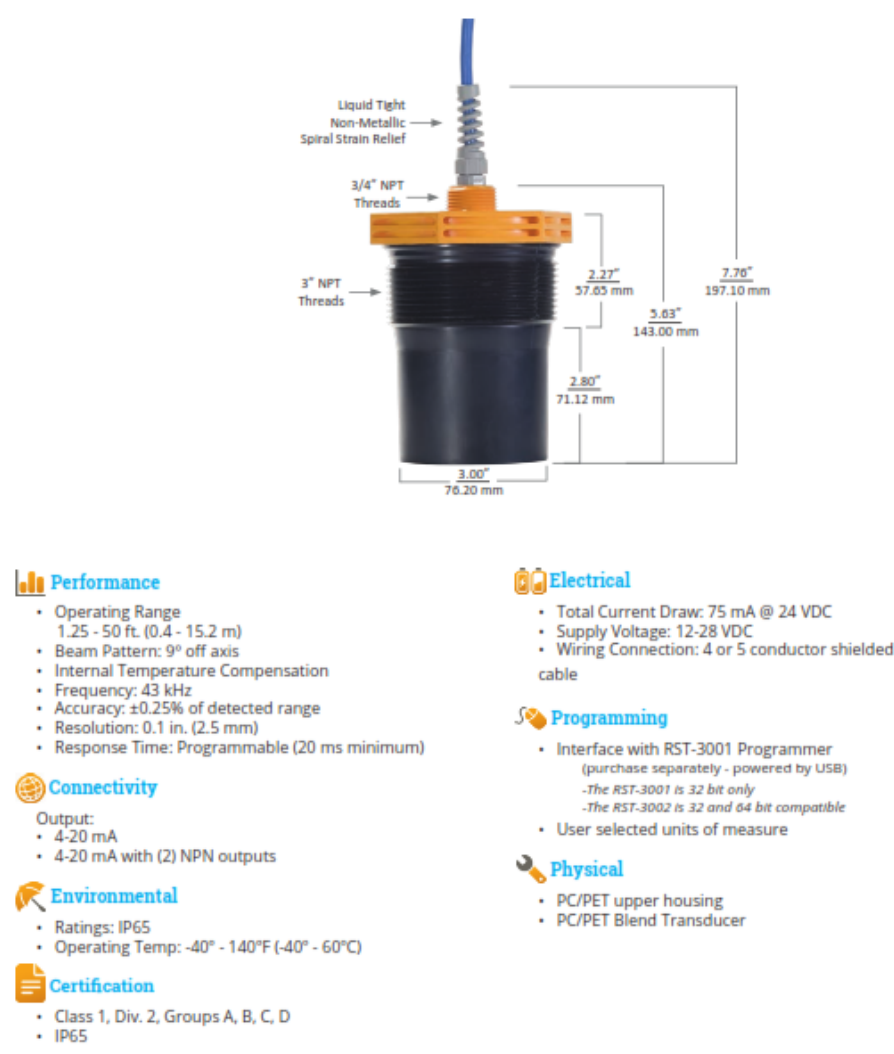

APGin" Automation Products Group, Inc. | 888.525 .7300 | sales@apgsensors.com | mww.apgsensors.com

Fig 6. Ultrasonic Sensor Specification (APG IRU-3435 C6)

\subsection{Sensor Using}

For this study, we are using an ultrasonic sensor with model no. IRU-3435 C6 [Figure 6] manufactured by "Automation Products Group (APG)" it is a USA based automation product manufacturing company. This sensor provides a non-contact method of detecting presence/absence detection, proximity and distance and works on solids and liquids. Sensor is suitable for this study because, it has maximum operating range of 50 foot $(15.2 \mathrm{M})$ and we need to design a hazard detection system with operating range of $42 \mathrm{foot}$, as described in the previous chapter of this paper. It will work in supply voltage ranging 12 to 18 VDC with beam pattern $9^{\circ}$ off axis. The sound frequency is $43 \mathrm{kHz}$ and the accuracy of detected range will be $\pm 0.25 \%$.

It is programmable for user defined parameters and no need of always connected to a data processing unit (Ex. Computer) if data monitoring on the screen is not required. It has NPN output option also that is why, it is capable to send information directly to the hazard indication equipment like speaker, LED bulb, vibrator, analog / digital display etc. It is designed for using in harsh environment with operating temperature ranges from $-40^{\circ} \mathrm{C}$ to $60^{\circ} \mathrm{C}$ and IP65 waterproof rating maximum operating range of 50 foot $(15.2 \mathrm{M})$ and we need to design a hazard detection system with operating range of $42 \mathrm{foot}$, as described in the previous chapter of this paper. It will work in supply voltage ranging 12 to $18 \mathrm{VDC}$ with beam pattern $9^{\circ}$ off axis. The sound 
frequency is $43 \mathrm{kHz}$ and the accuracy of detected range will be $\pm 0.25 \%$. It is programmable for user defined parameters and no need of always connected to a data processing unit (Ex. Computer) if data monitoring on the screen is not required. It has NPN output option also that is why, it is capable to send information directly to the hazard indication equipment like speaker, LED bulb, vibrator, analog / digital display etc. It is designed for using in harsh environment with operating temperature ranges from $-40^{\circ} \mathrm{C}$ to $60^{\circ} \mathrm{C}$ and IP65 waterproof rating.

\subsection{Position of Sensor on the Vehicle}

Previously we already discussed about width and maximum speed of construction equipment on the construction site. Width of the vehicle plays a very important role in decision-making of position and minimum number of sensors used to cover maximum area of inspection. For this study we are taking Excavator with model number 650D LC from John Deere construction equipment company. Excavator width is 12.25 foot [Table 1]. The width of equipment is use for checking extra area cover by the ultrasonic beam. However, this area is different for different width equipment. Since the sensor module was able to deliver the correct range details, other properties were mentioned for a simplified anti-collision device. Sometimes the easiest configuration for an anti-collision ultrasound sensor model is with an only one sensor at the front of a vehicle and an only one sensor at the rear. Scenarios such as this illustrate one of the most negative aspects of ultrasound sensors, which is the significant variance in the width of the detector cone depending on the form and structure of the subject being tracked. The inclination at the vertex of the detector cone was observed $18^{\circ}$ up to maximum coverage distance (50 foot in this case). To make sure that the anything in the vehicle's path is Recognized, the cone should cover the whole area immediately in front of the vehicle. It sets the range from the front of the vehicle where the sensor must detect for object / human (using a $18^{\circ}$ cone and a $42^{\prime}$ detection range). The issue with this configuration is that the detection cone (as it is much larger) now detects object / human which will not really be in the route of the vehicle. As shown in Figure 7, a 12' 3" wide vehicle Loaded with an ultrasound sensor, it would be mandatory 6 " on either side or a 13'- 3" broad path to prevent false detection. This kind of framework will not give false detection since standard construction roadways are $15^{\prime}$ to $18^{\prime}$ wide ${ }^{(11)}$.

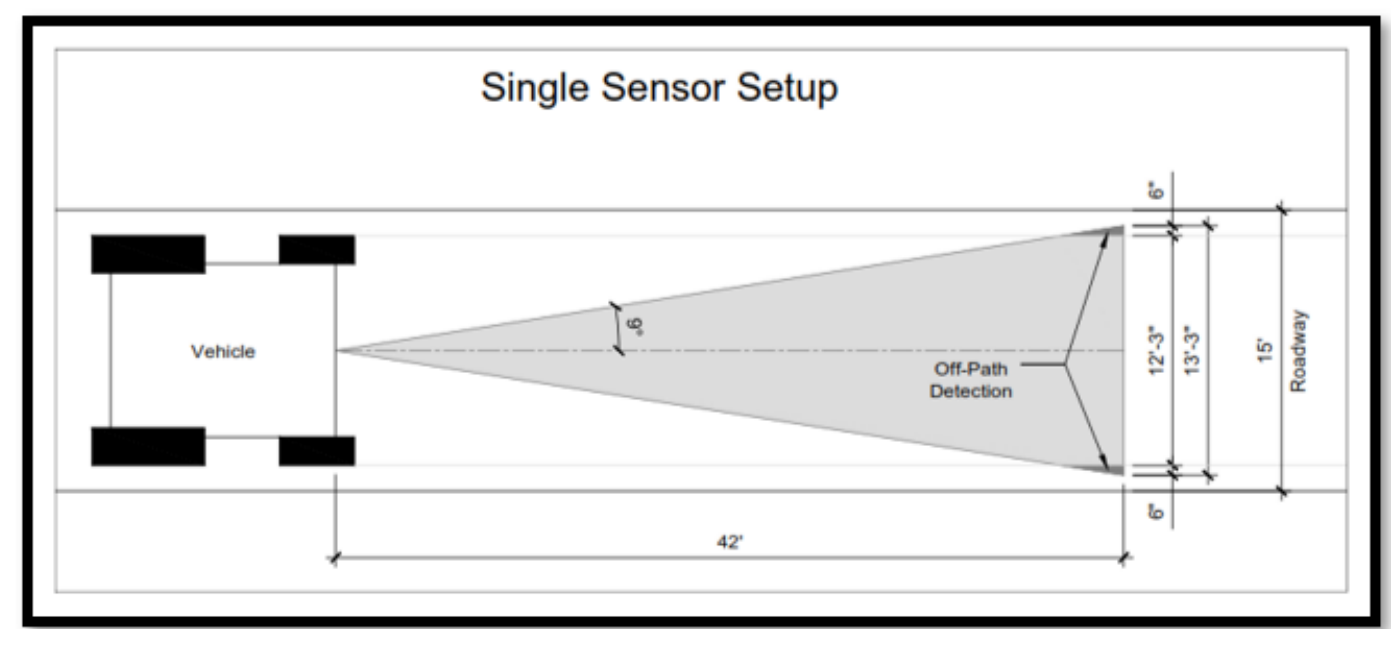

Fig 7. Single Sensor Setup

However, this setup is not covering full path of the vehicle, more than one sensor can be used to cover full path. If we assume, a unit of three ultrasound sensors on the front of the vehicle [Figure 8], we can cover $80 \%$ of the vehicle's path. But now ultrasound sensor would require 1'-2" on either side or a 14'-7' broad path to prevent false detection. In this case also we are not exceeding the standard construction road width. So, this setup would not give false detection. The increasing complexity of the entire process will be the downside of using multiple sensors on the same vehicle.

\section{Hardware Design}

The core components in the proposed early warning system are Power Source, Sensor, Trigger mechanism, warning system. The internal battery of construction equipment, on which sensor to be installed, will be the power source for the proposed early warning system. Since, power requirement of selected sensor and warning system is 24 volts and the standard battery capacity 


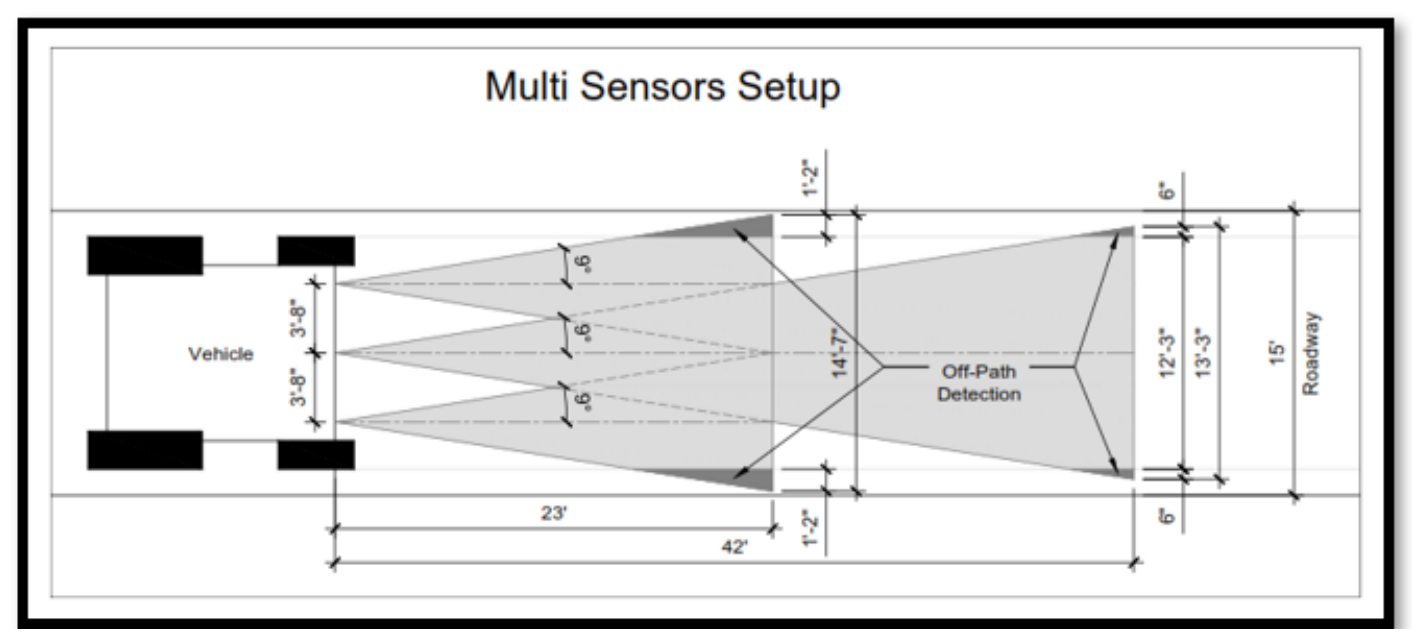

Fig 8. Multi Sensors Setup

of construction equipment manufactured by very known manufactures like Volvo, Hitachi, Doosan, Liebherr, Caterpillar, Case, Cat, John Deree etc. is also 24 volts, the internal battery of equipment is ideal for act as a power source for proposed system. A 24-volt DC relay manufactured by Schneider with model number RXM2LB2BD [Figure 9] will be used as a signal trigger mechanism. The work of the relay in this system is to receives signal from the sensor and command warning system to turn off or on. A 24-volt DC red color revolving warning light manufactured by Q-Light with model number S80RLR [Figure 9] will be used as a warning system to provide visual warning to the operator of the equipment.
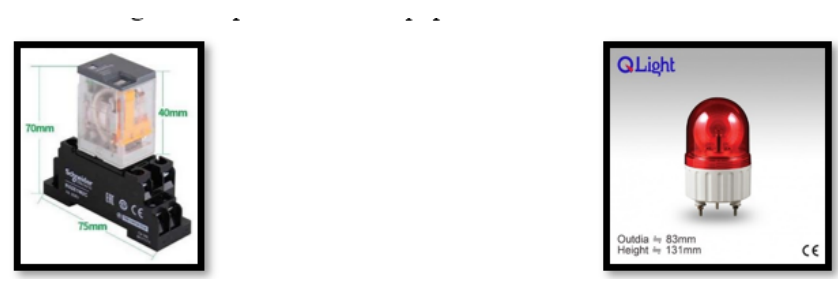

Fig 9. (a) Relay; (b) Revolving Warning Light

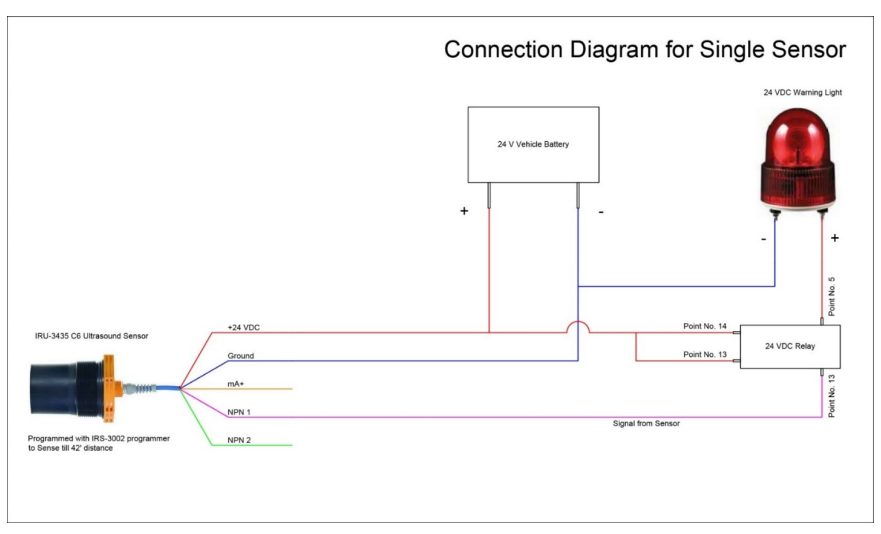

Fig 10. Connection Diagram for Single Sensor Setup 


\subsection{Single Sensor Connection}

From the selected ultrasound sensor 3 wires (+24 VDC, Ground and NPN 1) out of 5 wires can fulfill the requirements of proposed early warning system for struck-by hazard. The connections between components of the single sensor system are shown in the Figure 10.

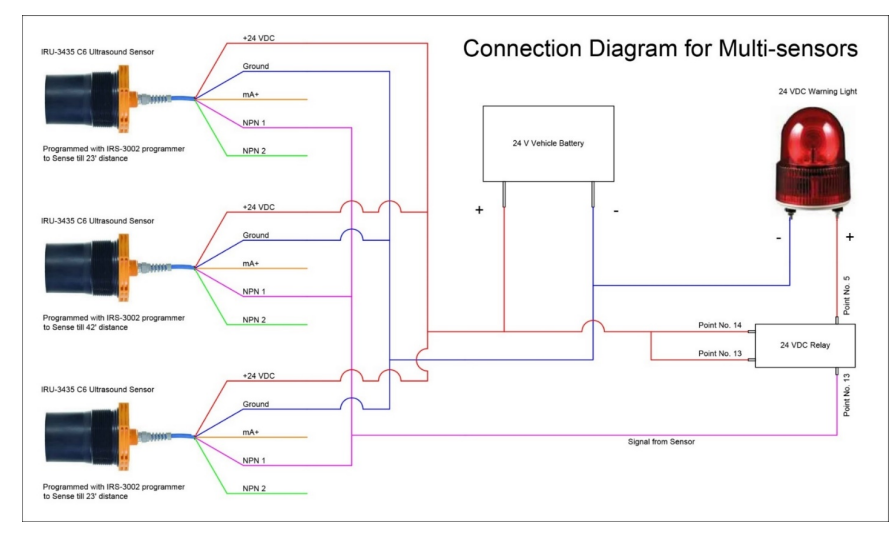

Fig 11. Connection Diagram for Multi Sensors Setup

\subsection{Multi Sensors Connection}

Since, three ultrasound sensors are used in this setup then each sensor should work independently to detect object in the path of the vehicle. So that, all the three sensors will be connected in the parallel connection method. The main advantage of parallel connection method is that, when object detected by any one of the sensors, warning light will be turn on. If more than three sensors are required to connect in the same system, then the extra sensors can be connected in the system by parallel connection method without affecting existing connection system. The connections between components of the multi-sensor system are shown in the Figure 11.

\section{Conclusion and Future Work}

The proposed system can increase the safety at construction site from struck-by hazard by alerting the operator of construction vehicle. The system will give the visual and acoustical warning signals to the operator automatically in real time so that the operator could stop the vehicle before collision and increase the level of safety at the construction site. Ultrasound sensors can address distance related problems within the range of concentrations. However, unable to detect objects at sharp edges with a single sensor setup make ultrasound technology a poor choice. This issue has been solved by increased system complexity and emerge with more than one sensor. The sharp angle problems can be solved by using more than one sensor because, sharp edge for one sensor will not for another one. Ultrasound sensor can work independently and does not require any external processing power. Therefore, ultrasound sensor is the optimum choice to use at construction sites because of its independent working and less power consuming.

The proposed arrangement of sensors on the vehicle to be tested in the construction working environment to get practical outcome and to analyze the feasibility of proposed system in the real world. Testing the applicability of other sensor solutions in struck-by hazards, such as contact sensors, infrared sensors, active light systems, stereo vision systems, and others, would be part of future work. It would also explore the potential outcome of using ultrasound sensors in conjunction with many other sensors. Implementation cost aspect of the proposed system can be considered with cost benefit after implementation in a particular project to find the worthiness of the system in construction safety management.

\section{References}

1) Hinze J, Godfrey R. An Evaluation of Safety Performance Measures for Construction Projects. Journal of Construction Research. 2003;04(01):5-15. Available from: https://dx.doi.org/10.1142/s160994510300025x.

2) Teizer J, Allread BS, Fullerton CE, Hinze J. Autonomous pro-active real-time construction worker and equipment operator proximity safety alert system. Automation in Construction. 2010;19(5):630-640. Available from: https://dx.doi.org/10.1016/j.autcon.2010.02.009. 
3) Fang Q, Li H, Luo X, Ding L, Luo H, Rose TM, et al. Detecting non-hardhat-use by a deep learning method from far-field surveillance videos. Automation in Construction. 2018;85:1-9. Available from: https://dx.doi.org/10.1016/j.autcon.2017.09.018.

4) Kim H, Bang S, Jeong H, Ham Y, Kim H. Analyzing context and productivity of tunnel earthmoving processes using imaging and simulation. Automation in Construction. 2018;92:188-198. Available from: https://dx.doi.org/10.1016/j.autcon.2018.04.002.

5) Kim D, Liu M, Lee S, Kamat VR. Remote proximity monitoring between mobile construction resources using camera-mounted UAVs. Automation in Construction. 2019;99:168-182. Available from: https://dx.doi.org/10.1016/j.autcon.2018.12.014.

6) Kim D, Liu M, Lee S, Kamat VR. Trajectory Prediction of Mobile Construction Resources Toward Pro-active Struck-by Hazard Detection. Proceedings of the International Symposium on Automation and Robotics in Construction (IAARC). 2019;p. 982-988. Available from: https://doi.org/10.22260/ISARC2019/ 0131.

7) Yan X, Zhang H, Li H. Computer vision-based recognition of 3D relationship between construction entities for monitoring struck-by accidents. ComputerAided Civil and Infrastructure Engineering. 2020;35(9):1023-1038. Available from: https://dx.doi.org/10.1111/mice.12536.

8) Golovina O, Teizer J, Pradhananga N. Heat map generation for predictive safety planning: Preventing struck-by and near miss interactions between workers-on-foot and construction equipment. Automation in Construction. 2016;71:99-115. Available from: https://dx.doi.org/10.1016/j.autcon.2016.03. 008.

9) Hinze JW, Teizer J. Visibility-related fatalities related to construction equipment. Safety Science. 2011;49(5):709-718. Available from: https://dx.doi.org/ 10.1016/j.ssci.2011.01.007.

10) Park MW, Koch C, Brilakis I. Three-Dimensional Tracking of Construction Resources Using an On-Site Camera System. Journal of Computing in Civil Engineering. 2012;26(4):541-549. Available from: https://dx.doi.org/10.1061/(asce)cp.1943-5487.0000168.

11) Dutta T, Fernie GR. Utilization of ultrasound sensors for anti-collision systems of powered wheelchairs. IEEE Transactions on Neural Systems and Rehabilitation Engineering. 2005;13(1):24-32. Available from: https://dx.doi.org/10.1109/tnsre.2004.842366. 